UNIVERSIDADE DE SÃO PAULO

INSTITUTO DE GEOCIÊNCIAS

\title{
A INTRUSÃo ULTRAPOTÁSSICA INDAIÁ II, PROVÍNCIA ALCALINA ALTO PARANAÍBA (MG): \\ PROCESSOS MAGMÁTICOS DE SISTEMA ABERTO E IMPLICAÇÕES PETROGENÉTICAS
}

\section{NICHOLAS MACHADO LIMA}

Dissertação apresentada ao Instituto de Geociências de São Paulo como exigência parcial para a obtenção do título de Mestre em ciências Área de concentração: Petrologia Ígnea e Metamórfica

Orientador:Prof. Dr. Rogério Guitarrari Azzone

\section{SÃO PAULO}


Autorizo a reprodução e divulgação total ou parcial deste trabalho, por qualquer meio convencional ou eletrônico, para fins de estudo e pesquisa, desde que citada a fonte.

Serviço de Biblioteca e Documentação do IGc/USP

Ficha catalográfica gerada automaticamente com dados fornecidos pelo(a) autor(a) via programa desenvolvido pela Seção Técnica de Informática do ICMC/USP

Bibliotecários responsáveis pela estrutura de catalogação da publicação: Sonia Regina Yole Guerra - CRB-8/4208 | Anderson de Santana - CRB-8/6658

Machado Lima, Nicholas

A INTRUSÃO ULTRAPOTÁSSICA INDAIÁ II, PROVÍNCIA

ALCALINA ALTO PARANAÍBA (MG) : PROCESSOS MAGMÁTICOS DE SISTEMA ABERTO E IMPLICAÇÕ̃S PETROGENÉTICAS /

Nicholas Machado Lima; orientador Rogério

Guitarrari Azzone. -- São Paulo, 2018.

$183 \mathrm{p}$.

Dissertação (Mestrado - Programa de Pós-Graduação em Mineralogia e Petrologia) -- Instituto de Geociências, Universidade de São Paulo, 2018.

1. Kimberlito. 2. Rochas ultrapotássicas. 3. Contaminação crustal. I. Guitarrari Azzone, Rogério, orient. II. Título. 


\section{AGRADECIMENTOS}

Deixo aqui registrado meu agradecimento a todos que me auxiliaram na realização desse trabalho. Agradeço primeiramente a minha mãe Josane e meu pai Gil, assim como minha família e minha madrasta Alessandra. Por todo apoio e confiança durante o mestrado e em todo o caminho trilhado até chegar aqui. Sem eles nada disso seria possível.

Ao meu orientador Rogério Azzone por todo o conhecimento transmitido, por toda dedicação, disponibilidade e paciência ao me orientar durante a elaboração desse trabalho e durante a pós graduação como um todo. Sou muito grato por tudo.

À CAPES pela minha bolsa de mestrado, e a Fundação de Amparo à Pesquisa do Estado de São Paulo (projetos 2012/06082-6 e 2017/03768-8) por fornecer o auxílio financeiro para realização dessa pesquisa.

Aos Professores do IGc Usp, com quem também aprendi muito: Excelso Ruberti, Gaston Enrich, Patrício Munhoz, Renato de Moraes, Silvio Vlach e Valdecir Janasi, Obrigado por compartilhar seus conhecimentos.

Aos funcionários do IGc-USP pelo suporte durante todas as fases dessa pesquisa, em especial os técnicos que me auxiliaram nos processos analíticos diretamente: Marcos e Leandro (microssonda), Vinícius (laser ablation), José Paulo (FRX), Samuca (LTA) e Liliane (CPgeo).

Á minha namorada Flávia Lameck, por todo amor e carinho. Por estar ao meu lado, ouvindo minhas reclamações, e também comemorando as vitórias comigo, apesar de todos os sacrifícios e da distância que foram necessários para completar esse trabalho. Muito obrigado.

A Júlio Lopes pelo incentivo de tentar o mestrado, pelas discussões petrológicas, e por toda ajuda durante o mestrado e pela amizade desde os tempos de Rural. Sou muito Grato.

A Iuri Retamal (Zuri) pela amizade e pela ajuda quando cheguei a São Paulo, muito obrigado.

A todos os amigos e colegas da Pós Graduação do IGc com quem compartilhei dessa ótima convivência nesses últimos quase 3 anos, especialmente: à galera do Bosque (Fernando Prado, Thomas Akabane, Stephani Somekawa, Raquel Romão, Funga, John), Lina Maria, Anny Forero e Camila Sayuri. Obrigado pelas ajudas, conversas, desabafos, e momentos de descontração. 
Agradeço também aos Komodos do Crusp: Zé Renato, Marcelão, Piero, Ricardo, Jean, Muay Thai, Fabian, Carlão e toda a galera que passou perrengue comigo no alojamento (risos). Obrigado pelos papos, brejas e jogos de xadrez.

Por fim agradeço à Universidade de São Paulo e ao Instituto de Geociências da Usp pela inesquecível experiência, muito obrigado. 
"Discovery is the ability to be puzzled by simple things.”

- Noam Chomsky 


\section{RESUMO}

As intrusões Indaiá I e II (também referidas como Perdizes 3-A e 3-B) são corpos intrusivos hipoabissais ultrabásicos de pequeno porte, associados ao magmatismo cretácico da Província Alcalina Alto Paranaíba, oeste do Estado de Minas Gerais. Esta dissertação de mestrado objetivou compreender a gênese e processos de evolução relacionados a intrusão Indaiá II, cuja classificação ambígua entre kimberlito e kamafugito dividiu autores em trabalhos anteriores.. Também buscou-se discutir a possível vinculação genética com a intrusão vizinha, Indaiá I. Para tanto, foram realizadas novas análises petrográficas, geoquímicas e isotópicas de rocha total, e química mineral. A intrusão principal (Indaiá I) é classificada como um kimberlito do Grupo I. Já a intrusão satélite (Indaiá II) distingue-se quimicamente e petrograficamente, possuindo uma composição ultrapotássica, similar à kamafugítica, e apresenta menor concentração de macrocristais de olivina, diopsídio como o principal constituinte da matriz ( e não a monticellita como Indaiá I) e possui uma presença abundante de microenclaves félsicos. Estes enclaves apresentam estrutura estirada, e são constituídos principalmente por kalsilita/ nefelina, vidro devitrificado, diopsídio e flogopita. A presença de texturas sugestivas de desequilíbrio físico-químico como embayment e sieve em grãos de olivina e clinopiroxênio em Indaiá II são indicativas de processos de sistema aberto. A abundância de diopsídio na matriz e a substituição de olivina por clinopiroxênio nas bordas de macrocristais e microcristais apontam para um aumento da atividade de sílica no decorrer do processo de cristalização. A alta proporção de xenólitos crustais na rocha, totalmente transformados ou com evidências de fusão parcial, e a presença de apatitas aciculares nas suas cercanias, indicam a operação de um processo de contaminação crustal. Novos dados de química mineral e litogeoquímica de elementos maiores e traços corroboram esse processo. Os trends composicionais de minerais como espinélio e flogopita são bastante similares a ocorrências de kimberlitos contaminados registrados na literatura. Além disso, amostras de Indaiá II apresentam elevado C.I. (Contamination Index, 2,12-2,25), maior percentual de $\mathrm{SiO}_{2}, \mathrm{~K}_{2} \mathrm{O}$ e maior razão $\mathrm{Rb} / \mathrm{Sr}$ que a intrusão principal. Modelos de contaminação crustal foram efetuados a partir da mistura do fundido de Indaiá I e do fundido das rochas granitoides encaixantes. Os fundidos de Indaiá I e II foram obtidos pela extração do volume dos núcleos de macrocristais de olivina, considerados xenocristais em ambas as ocorrências, das análises de rocha total. A quantidade de olivina foi obtida através de análises modais, e a composição considerada foi obtida através de uma média das análises pontuais de microssonda eletrônica e LA-ICP-MS. O fundido da encaixante foi estimado utilizando-se as análises de rocha-total das encaixantes crustais da área e calculandose um fundido parcial desta rocha a $750^{\circ} \mathrm{C}$ e pressões entre $1-5 \mathrm{Kbar}$ com o software RhyoliteMelts (para elementos maiores). A composição de elementos-traço do fundido foi modelada por balanço de massa, a partir de coeficientes de partição compilados da literatura e a proporção de minerais no resíduo sólido obtida dos modelos por elementos maiores. Curvas de mistura entre elementos maiores e traços também parecem confirmar o processo. Novos dados isotópicos de ${ }^{87} \mathrm{Sr} /{ }^{86} \mathrm{Sr}$ e ${ }^{143} \mathrm{Nd} /{ }^{144} \mathrm{Nd}$ foram obtidos para estas intrusões, como também para a encaixante local. Curvas de mixing isotópico foram feitas para tentar constringir a quantidade de contribuição crustal nos magmas de Indaiá II. Nestes modelos, as amostras de Indaiá II fitam concordantemente às curvas de mistura entre os polos de Indaiá I e da encaixante. Concluimos que: 1) a intrusão Indaiá II representaria uma intrusão kimberlítica altamente contaminada, 2) a contaminação provavelmente ocorreu pela assimilação de fundidos anatéticos oriundos das principais rochas encaixantes crustais da área, 3) que Indaiá I e Indaiá II poderiam ter um mesmo magma progenitor, mas com diferentes graus de contaminação crustal.

Palavras-Chave: Kimberlitos, rochas ultrapotássicas, ,contaminação crustal. 


\begin{abstract}
The intrusions Indaiá I and II (also referred as Perdizes 3-A and 3-B) are hypoabissal ultrabasic bodies of small size associated with the Cretaceous magmatism of the Alto Paranaiba Alkaline Province, west of the Minas Gerais state. This master's dissertation aimed a better understanding of the genesis and the evolution processes related to the Indaia II intrusion, whose ambiguous classification between kimberlite and kamafugite divided the authors of former works. Also, it is discussed the possible genetic linkage of Indaiá II with the neighbor intrusion, Indaiá I. For this purpose, new petrographic, whole rock geochemical, isotopic and mineral chemistry analyses were made. The main intrusion (Indaiá I) was classified as a groupI kimberlite. The satellite intrusion, Indaiá II, is petrographically and chemically distinct of the main one, having a ultrapotassic composition, similar to those of kamafugites, and presenting lower volumes of olivine macrocrysts, diopside as the main matrix phase (instead of monticellite as found in Indaiá I), and an abundant presence of felsic microenclaves. These enclaves present elongated structure and they mainly have kalsilite, devitrified glass, diopside and phlogopite. The presence of textures indicative of physical-chemical disequilibrium, such as embayment and sieve in olivine and clinopyroxene grains from Indaiá II are indicative of an open system process. The high amounts of diopside in the matrix and the substitution of the rims of olivine macro- and microcrysts by clinopyroxene point to an increase in the silica activity during the crystallization. The high proportion of crustal xenoliths in the rocks, most of these totally transformed or with evidences with partial melt, and the presence of acicular apatite in their border regions, indicate the action of crustal contamination processes. New mineral chemistry and whole rock geochemical (major and trace elements) data corroborate this process. The spinel and phlogopite compositional trends are very similar with those from contaminated kimberlitic occurrences registered in the literature. Moreover, samples from Indaiá II have high Contamination Index (C.I., 2.12-2.25), greater amounts of $\mathrm{SiO}_{2}, \mathrm{~K}_{2} \mathrm{O}$ and higher $\mathrm{Rb} / \mathrm{Sr}$ ratios than those from the main intrusion. Crustal contamination models were developed considering a mixing between the melt of Indaiá I and the partial melt of the granitoid host rocks of the area. The composition of melts from Indaiá I and II were calculated by the extraction of the amount of the cores of olivine macrocrysts, considered xenocrysts in both occurrences, from the whole-rock compositions. The amount of olivines was taken from modal concentrations and the considered composition was obtained by the average of electron microprobe and laser ablation inductively coupled plasma mass spectrometry (LA ICP-MS) analyses. The major element composition of the partial melt of the host rock was estimated using the algorithm RhyoliteMelts. For these models, we considered the whole-rock compositions of the main host rocks of the area and used $750^{\circ} \mathrm{C}$ and $1-5 \mathrm{Kbar}$. The trace element composition of the host rock partial melts was modeled by mass balance calculations, using partition coefficients from the literature and the proportion of minerals in the solid residue obtained for the major element models. After the calculation of these liquid compositions, mixing curve models using major and trace element compositions were made and they are concordant with the crustal contamination processes. New ${ }^{87} \mathrm{Sr} /{ }^{86} \mathrm{Sr}$ and ${ }^{143} \mathrm{Nd} /{ }^{144} \mathrm{Nd}$ isotopic data were obtained for Indaiá I and II intrusions, as well as for the local host rock. Isotopic mixing curves were also made trying to constrain the amount of crustal contribution in Indaiá II magmas. In these models, Indaiá II samples fit concordantly with the mixing curves having Indaiá I and the host rock ratios as the main poles. We conclude that 1) Indaiá II is representative of a highly contaminated kimberlitic intrusion, 2) the contamination possibly occurred by the assimilation of the anatetic melts from the main crustal host rocks of this area and 3) that Indaiá I and Indaiá II could have the same parent melt, but with different degrees of crustal contamination.
\end{abstract}

Keywords: kimberlites, ultrapotassic rocks, crustal contamination 


\section{SUMÁRIO}

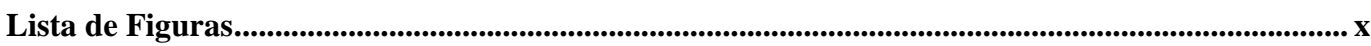

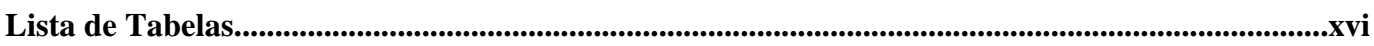

1. Introdução ……......................................................................................................................................... 1

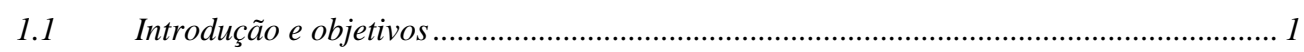

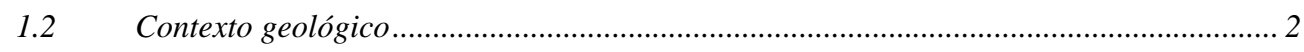

1.2.1 Província Ígnea Alcalina Alto Paranaíba ........................................................................ 2

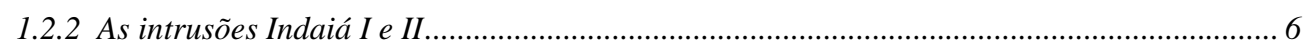

2. Metodos analíticos...................................................................................................................................... 10

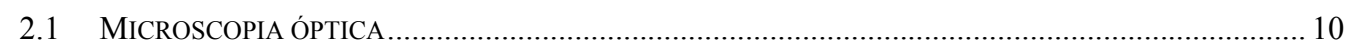

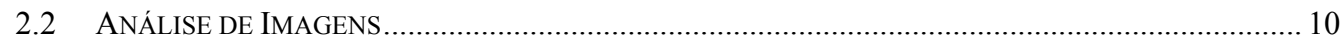

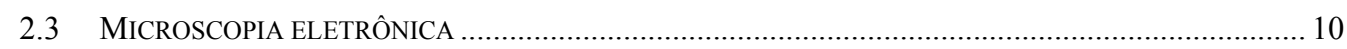

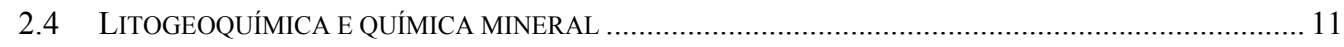

2.4.1 Preparação de amostras ....................................................................................... 11

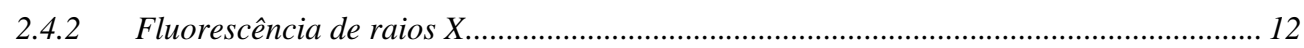

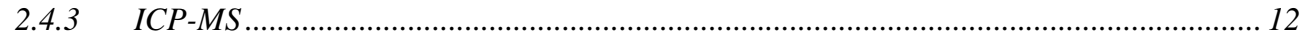

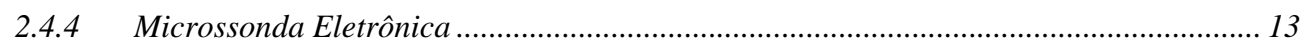

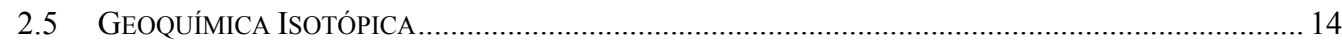

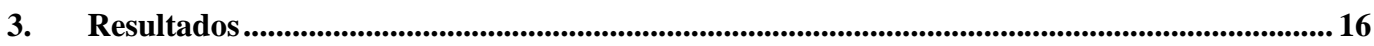

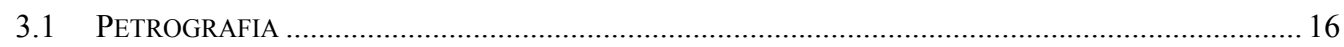

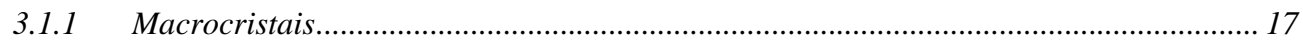

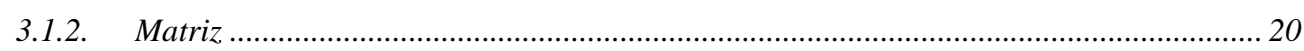

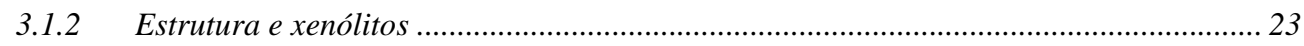

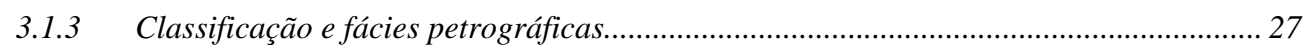

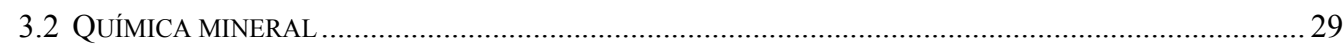

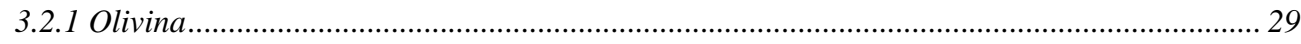

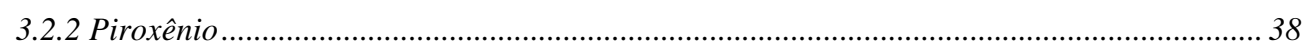

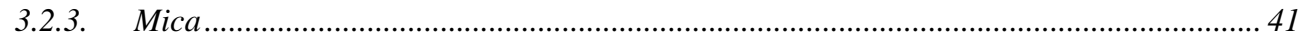

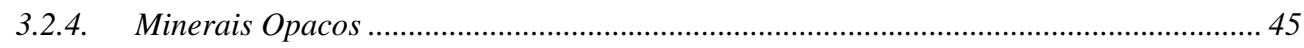

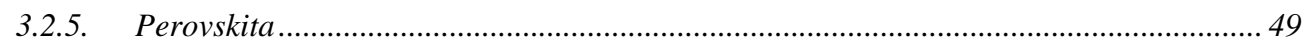

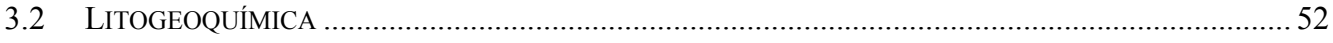

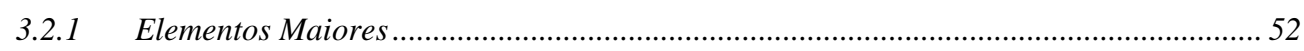

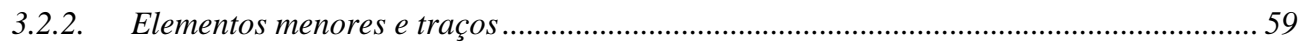

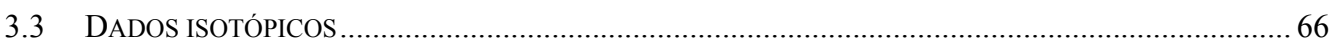

4. Discuss

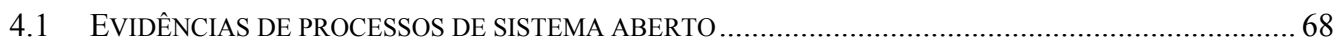

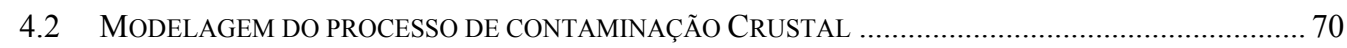


4.2.1 Modelagem do contaminante …...........................................................................

4.2.2 Composição dos fundidos de Indaiá I e II ........................................................................73

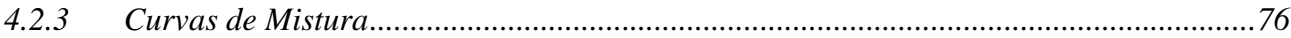

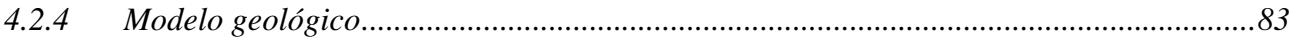

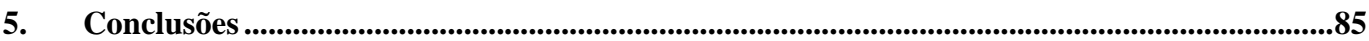

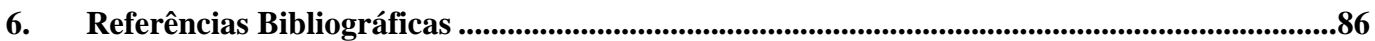

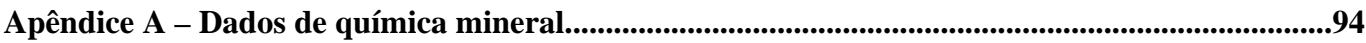

Apêndice B Dados de litogeoquímica e isótopos em rocha total..........................................................156

Apêndice C - Fundidos calculados e coeficientes de partição.........................................................162 


\section{LISTA DE FIGURAS}

Figura 1. Localização e idades de algumas ocorrências magmáticas da Província Ígnea do Alto Paranaíba. extraído de Guarino et al. (2013)

Figura 2 Mapa geológico do Supercampo kimberlítico Coromandel-Três Ranchos com intrusões de afinidade kimberlítica indicada pelos triângulos pretos. Círculo amarelo mostrando a intrusão alvo. Modificado de Cabral Neto et al. (2017). .8

Figura 3 a) Mapa geológico esquemático modificado de Féboli e Pinheiro (2014). b) Mapa geológico esquemático das intrusões Indaiá I e II, modificado de Meyer et al. (1991). 9 Figura 4 Aspecto macroscópico das rochas da intrusão Indaiá II em amostra de mão. Notar a presença de xenólito crustal e microenclaves estirados (setas vermelhas) definindo estrutura orientada, e a matriz de coloração mais clara em suas proximidades. 16

Figura 5 Macrocristais de olivina observados sob microscópio óptico: a) e b) Setas amarelas e contorno vermelho indicando faixa com micro inclusões nas bordas dos macrocristais, em contraste com núcleos mais límpidos. Polarizadores em paralelo. c) Macrocristal apresentando microestrutura de embayment indicado por setas amarelas. Polarizadores em paralelo. d) Texturas tipo sieve em macrocristal subédrico. e) e f) Olivina apresentando feições de corrosão e substituição por clinopiroxênio. Polarizadores em paralelo e cruzados, respectivamente. Siglas utilizadas: Ol - olivina, Cpx - clinopiroxênio. 18

Figura 6 Zonamentos abruptos observados em macrocristais de olivina em imagens de elétrons retroespalhados: a) Macrocristal de olivina apresentando zonamento abrupto normal com núcleo mais rico em $\mathrm{Mg}$ (escala equivale a $100 \mu \mathrm{m})$. b) Macrocristal de olivina apresent Zonamentos abruptos observados em macrocristais de olivina em imagens de elétrons retroespalhados: a) Macrocristal de olivina apresentando zonamento abrupto normal com núcleo mais rico em $\mathrm{Mg}$ (escala equivale a $100 \mu \mathrm{m}$ ). b) Macrocristal de olivina apresentando zonamento abrupto reverso com bordas mais ricas em $\mathrm{Mg}$ que o núcleo (escala equivale a $500 \mu \mathrm{m}$ ).

Figura 7 Figura 7. Aspectos texturais e mineralógicos da matriz da intrusão Indaiá II. a) Visão geral da matriz; b) detalhe dos constituintes da matriz: diopsídio (Di), titanomagnetita (TiMag), perovskita (Prv) e apatita (Ap). c) microcristais de flogopita ricos em inclusões d) "necklace" de perovskita formado ao redor de microcristal de olivina. e) espinélio avermelhado apresentando coroa de óxidos e f) microcristal de flogopita apresentando inclusões de apatita, diopsídio e opacos. Luz polarizada em (a, c, d, e) e imagens de retroespalhados em (b, f). 21 Figura 8 Aspectos petrográficos da intrusão Indaiá II. a) Microcristal euédrico apresentando zonamento reverso gradual, com núcleo mais pobre em Mg. b) Microcristal euédrico apresentando zonamento complexo, com núcleo e zona intermediária apresentando zonamento abrupto normal e borda rica em $\mathrm{Mg}$. c) Microcristais de olivina (setas vermelhas) apresentando feições reacionais próximas a microenclave félsico. d) Microcristais de olivina parcialmente substituindo por serpentina (bordas esverdeadas) e flogopita (borda cor de cobre, seta vermelha). e) e f) Microcristal de olivina (com contornos destacados) apresentando feições de corrosão e substituição por clinopiroxênio e flogopita. Imagens de elétrons retroespalhados em (a) e (b). Luz polarizada em (c, d, e) e polarizadores cruzados (f). Siglas utilizadas: Ol - olivina, Cpx-Clinopiroxênio, Phl - flogopita. .. 22

Figura 9 Relações texturais e estruturais entre matriz e microenclaves félsicos: a) e b) Alinhamento de microenclaves e microcristais de olivina formando estrutura sugestiva de fluxo (setas indicando direção de fluxo). b) Detalhe de microenclave félsico mostrando grãos de kalsilita/ nefelina imersos em material amarelado amorfo, possivelmente vidro devitrificado. d) Microclave substituído por grãos de clinopiroxênio com textura sieve e 
flogopita. e) Imagem de elétrons retroespalhados de contato entre matriz e microenclave substituído por diopsídio com textura sieve. f) Microenclave félsico apresentando substituição por flogopita e a presença de grão de apatita de hábito ocelar, e granulação relativamente grossa. Luz polarizada em (a, b, d, f) e imagens de elétrons retroespalhados em $(b, c)$.

Figura 10 . a) e b) Fotomicrografias ilustrando reação entre borda de microcristal de olivina e microenclave félsico. A olivina apresenta corrosão (realçada nas figuras) e cristalização de microcristal de flogopita poiquílitica. Luz polarizada e polarizadores cruzados, respectivamente. c) Imagem de elétrons retroespalhados mostrando grãos de kalsilita com feições de desequilíbrio e parcialmente substituídos por flogopita, no interior de um microenclave.

Figura 11 Feições petrográficas observadas em microenclaves e xenólitos crustais de Indaiá II: a) e b) Microenclave félsico texturalmente similar a buchito. Apresenta zona de influência na matriz, colocada em evidência apela linha tracejada amarela, cuja granulação se torna mais fina e mais rica em diopsídio nas proximidades do enclave. é notável também o grão ocelar de apatita (seta vermelha), de granulação bem mais grossa que os outros constituintes do microenclave. c) Xenólito crustal parcialmente fundido apresentando grãos proeminentes de apatita (Ap), similares ao constatado nos xenólitos félsicos. Também são identificáveis grãos de flogopita (Phl), e possível actinolita (Act). d) Xenólito crustal contendo grãos de apatita acicular (Ap) e analcima (Anl), circundados por vidro amarelado. e) Borda de xenólito crustal rica em analcima, flogopita mimetizeo fundido, e uma borda mais externa que apresenta kalsilita (Ks). e) Xenólito crustal apresentando digestão de grão de feldspato maior, e cristalização de de novas ripas de k-feldspato junto ao vidro. Luz polarizada em (a, b, c, d) e imagens de elétrons retroespalhados em $(e, f)$..... ..26 Figura 12 Variação composicional das olivinas de Indaiá II em função dos teores de $\mathrm{TiO}_{2}, \mathrm{Al}_{2} \mathrm{O}_{3}, \mathrm{CaO}, \mathrm{NiO}, \mathrm{Cr}_{2} \mathrm{O}_{3}$ (\% em massa) e do membro final forsterita (Fo). Representada em boxplots separadas em grupos texturais: 1Núcleos de macrocristais,2- bordas de macrocristais, 3- Núcleos de Microcristais euédricos/subédricos, 4- Bordas de microcristais euédricos/subédricos, 6- Zonas reacionais internas a macrocristais ("manchas"), 7- Grãos da matriz, 8- Xenocristais francos

Figura 13 Diagramas divariantes de $\mathrm{Mg} \#[\mathrm{Mg} /(\mathrm{Mg}+\mathrm{Fe})$, em prop. Moleculares] vs. a) $\mathrm{NiO}$, b) $\mathrm{CaO}$ e c) $\mathrm{MnO}$ e de d) $\mathrm{CaO}$ vs $\mathrm{NiO}$, ilustrando a variação composicional dos grãos de olivina de Indaiá II. Tendências e grupos: I) núcleos e xenocristais do manto definindo uma "mantle trend"(grupo representado pela linha pontilhada preta, II) bordas definindo "melt trend" (linha pontilhada vermelha), e III) zona reacionais internas a macrocristais (“manchas"), caracterizadas por enriquecimento em $\mathrm{MnO}$ e $\mathrm{CaO}$ e empobrecimento em $\mathrm{MgO}$ (seta roxa). Dados em porcentagem em massa.

Figura 14 Diagramas divariantes de elementos menores e traço analisados por LA-ICP-MS ilustrando as diferenças composicionais entre bordas e núcleos de olivina. Núcleos representam círculos pretos e bordas os triângulos vermelhos. Dados em ppm.

Figura 15 a) Concentrações médias das análises de elementos menores e traço em olivina obtidas via LA-ICP-MS divididas em núcleos e bordas. As bordas são enriquecidas em in $\mathrm{Zr}$, Li , Sc, P, Na, Al,Ti, Cr, Ca e Mn. Já os núcleos são enriquecidos em $\mathrm{Nb}, \mathrm{Zn}, \mathrm{V}$, Co e Ni. b) Variação composicional de núcleos de olivina em relação a V/Sc vs Ni como indicador de fusão no manto em condições oxidantes (Foley et al. 2013). c) Composição de núcleos de olivina em relação a Ca vs Ti como indicado da natureza do agente metassomático na fonte mantélica. Dados em ppm. ..36 
Figura 16 Diagramas divariantes Zn vs Li e Ti vs Li indicativos de incorporação de material crustal reciclado na fonte mantélica (tendências segundo Foley, 2013; dados em ppm).

Figura 17 a) a c) Diagramas de classificação dos piroxênios segundo Morimoto (1988). Abreviações: $\mathrm{Q}=\mathrm{Ca}+\mathrm{Mg}+\mathrm{Fe} 2+; \mathrm{J}=2 \mathrm{Na}$; WEF-(Wo,En,Fs): Wo- wollastonita; En- enstatita; Fs- ferrosilita; Ae- egirina. d) Comparação da composição de Ti e Al (em átomos por fórmula unitária, a.p.f.u) dos piroxênios de Indaiá II com os dos kamafugitos de Brasil e Itália (Tappe, Foley e Pearson, 2003).....

Figura 18 Diagrama divariante ilustrando possíveis substituições nos grãos de diopsídio da matriz e enclaves. Dados em apfu. Mesma simbologia da figura 17 40

Figura 19 a) Diagrama ternário de classificação das flogopitas de Indaiá II, comparando outras ocorrências da APAP e da Província Serra do Mar, SE do Brasil (Melluso et al., 2008).b) Diagrama divariante ilustrando a correlação entre a incorporação de $\mathrm{Fe}^{3+}$ e a presença de $\mathrm{Si}$ e $\mathrm{Al}$ em sítios tetraédricos (dados em apfu). c) Diagrama Si vs $\mathrm{Al}^{\mathrm{IV}}$ mostrando a deficiência nesses elementos no sítio tetraédrico. Área em cinza representa a composição das micas de outras ocorrências brasileiras conhecidas (Morbidelli et al., 1995). 42

Figura 20 Diagramas divariantes mostrando as prováveis substituições encontradas nas flogopitas de Indaiá II. a) Substituição de $\mathrm{K}+\mathrm{Si}$ por $\mathrm{Ba}+\mathrm{Al}$ (em apfu) devido a incorporação do componente kinoshitalita e b) Incorporação de Ti via substituição acoplada deixando o sítio $M$ com vacância.

Figura 21 Diagrama $\mathrm{Al}_{2} \mathrm{O}_{3}$ vs $\mathrm{TiO}_{2}$ (\% em peso) ilustrando a variedade composicional dos grãos de flogopita analisados em Indaiá II. Para comparação estão representados os campos composicionais das flogopitas de mafuritos, uganditos e kimberlitos da APAP, compilados de Araújo et al. (2001), e os campos representativos dos kimberlitos mais contaminados (Di-Mel-Phl kimberlito) e menos contaminados (Mo-Phl-Srp kimberlito) por xenólitos graníticos de Caro et al. (2004). Mesma simbologia da figura 20. 44

Figura 22 Trends evolutivos dos espinélios projetados nas faces do prisma reduzido do espinélio (modificado de (Mitchell, 1986). Os espinélios da intrusão Indaiá II apresentam evolução compatível com o trend magmático II dos kimberlitos. Dados do prisma central apresentam apenas os trends indicados por Mitchell (1986)............. 46 Figura 23 Trends evolutivos dos espinélios projetados nas faces do prisma oxidado do espinélio (modificado de (Mitchell, 1986). Os espinélios da intrusão Indaiá II apresentam evolução compatível com o trend magmático II dos kimberlitos. Dados do prisma central apresentam apenas os trends indicados por Mitchell (1986). 47 Figura 24 Classificação das perovskitas analisadas nos diagramas de componentes moleculares a) PerovskitaTausonita-Loparita e b) Perovskita-Lueshita-Loparita (calculados segundo Locock e Mitchell, 2018), mostrando que os grãos analisados aproximam-se do membro ideal $\mathrm{CaTiO}_{3}$. 50 Figura 25 Diagramas bivariantes mostrando a relação entre a fugacidade de oxigênio $\left(\mathrm{fO}_{2}\right)$ calculada e a concentração de alguns óxidos na perovskita. Fugacidades em $\Delta \mathrm{NNO}$ e óxidos em \% em massa. 51 Figura 26 . Rochas das intrusões Indaiá I e II e encaixantes classificadas nos diagramas de rochas vulcânicas baseado em elementos maiores: a) Le Bas (1986) e b) De la Roche et al (1980)...............................................54 Figura 27 Campos de classificação de rochas ultrapotássicas baseados em Foley et al.(1987). Os campos designados são representativos de rochas do Grupo I (Lamproitos), Grupo II (kamafugitos) e Grupo II (Leucititos ultrapotássicos)...

Figura 28 Diagramas bivariantes ilustrando a variação composicional dos elementos maiores de Indaiá I e II e da encaixante em função de $\mathrm{MgO}$ (\% em peso), e comparação com os campos referentes a composição de kimberlitos, 
kamafugitos e flogopita picritos (lamprófiros ultramáficos) da APAP. Dados compilados a partir de Gomes e Comin-Chiaramonti (2005) e Guarino et al. (2013).

Figura 29 Diagramas divariantes ilustrando a variação composicional dos elementos maiores da Intrusão Indaiá II, tendo $\mathrm{MgO}$ como índice de diferenciação. Os dados estão representados em percentagem em massa. As setas tracejadas representam possíveis tendências lineares de evolução

Figura 30 . Diagramas bivariantes ilustrando a variação composicional dos elementos maiores da Intrusão Indaiá II, tendo $\mathrm{SiO}_{2}$ como índice de diferenciação. Os dados estão representados em percentagem em massa. As setas tracejadas representam possíveis tendências lineares de evolução. .58

Figura 31 Diagramas bivariantes ilustrando a variação composicional dos elementos compatíveis em Indaiá I e II, tendo $\mathrm{MgO}$ como índice de diferenciação (elementos compatíveis em ppm e $\mathrm{MgO}$ em \% em massa).

Figura 32 Diagramas bivariantes ilustrando a variação composicional dos elementos de alto potencial iônico (HFSE) em Indaiá I e II, tendo MgO como índice de diferenciação (HFSE em ppm e MgO em \% em massa)...61 Figura 33 Diagramas bivariantes ilustrando a variação composicional dos elementos litófilos (LILE) em Indaiá I e II, tendo como a $\mathrm{SiO}_{2}$ como índice de diferenciação (LILE em ppm e $\mathrm{SiO}_{2}$ em \% em massa).

Figura 34 . Amostras de Indaiá I e II e das rochas encaixantes plotadas nos diagramas: a) Spidergram normalizado para o manto primitivo segundo McDonough e Sun (1995) e b) diagramas de elementos terras raras também normalizado pelo manto primitivo de McDonough e Sun (1995).

Figura 35 Diagramas divariantes ilustrando a relação entre a razão $\mathrm{Gd} / \mathrm{Lu}$ e $\mathrm{SiO}_{2}$ (a) e $\mathrm{Gd} / \mathrm{Lu}$ e $\mathrm{Pb}$, que segundo Le Rouex et al. (2003) seriam indicadores de contaminação crustal.

Figura 36 Diagrama ${ }^{87} \mathrm{Sr} /{ }^{86} \mathrm{Sr}$ vs. $\varepsilon N d$ ilustrando os diversos campos isotópicos referentes às rochas da Província Alcalina do Alto Paranaíba e outras ocorrencias de rochas alcalinas brasileiras e em outros países, como as ocorrencias de kimberlitos do grupo I e II da áfrica do sul, kamafugitos-tipo de ugea, kimberlitos de Braúna (Brasil), rochas vulcânicas da Ilha de Trindade. Também foi incluídos um vetor referente a possível contaminação por contribuição crustal. Diagrama modificado de Guarino et al. (2013).

Figura 37 Diagrama baseado em Gudfinnson e Presnall (2005) para estimativa de pressão de geração dos fundidos de Indaiá I a partir da fusão de um peridotito carbonatado. Campos referentes a kimberlitos e kamafugitos da APAP. Modificado de Guarino et al. (2013). . .75

Figura 38 Diagrama $\mathrm{MgO} / \mathrm{CaO}$ vs $\mathrm{SiO}_{2} / \mathrm{MgO}$ para as rochas de Indaiá I e II, com os campos e trends definidos por Sparks et al. (2009), mostrando tendência coerente com a contaminação crustal. .75

Figura 39 Diagrama pseudoternário proposto por Sparks et al. (2009) para representar fundidos kimberlíticos a 1 kbar e pressões de saturação em $\mathrm{CO}_{2}$ e $\mathrm{H}_{2} \mathrm{O}$. Nele estão representadas os fundidos reconstruídos de Indaiá I e II e do fundido contaminante. Uma linha de amarração esta representada entre o fundido não contaminado proposto e o contaminante granítico . .77

Figura 40 Diagramas bivariantes apresentando linhas de mistura de elementos maiores formadas tendo como polos: o fundido calculado de Indaiá I e o fundido calculado da encaixante crustal. Também representados os fundidos de Indaiá I calculados por Guarino et al. (2013), e as composições de rocha total de indaiál e da encaixante. As porcentagens nos gráficos referem-se ao percentual de incorporação de material crustal (dados em $\%$ em peso)

Figura 41 Diagramas bivariantes apresentando linhas de mistura de elementos-traço e $\mathrm{SiO}_{2}$, tendo como polos: o fundido calculado de Indaiá I e o fundido calculado da encaixante crustal. Também representados os fundidos de 
Indaiá I calculados por Guarino et al. (2013), e as composições de rocha total de Indaiá I e da rocha encaixante. As porcentagens nos gráficos referem-se ao percentual de incorporação de material crustal (dados dos elementostraço em ppm e de $\mathrm{SiO}_{2}$ em \% em massa). 80

Figura 42 Curvas de mixing de ${ }^{87} \mathrm{Sr} /{ }^{86} \mathrm{Sr}$ vs $\mathrm{SiO}_{2}$ e $\mathrm{K}_{2} \mathrm{O}$ tendo como polos: o fundido calculado de Indaiá I e o fundido calculado da encaixante crustal. Também representados os fundidos de Indaiá I calculados por Guarino et al. (2013), e as composições de rocha total de Indaiá I e da encaixante. As porcentagens nos gráficos referem-se ao percentual de incorporação de material crustal (dados de elementos maiores em \% em massa). Os dados calculados de Indaiá II fitam a curva de mistura, confirmeo o processo de contaminação crustal. 81

Figura 43 Diagrama ${ }^{87} \mathrm{Sr} /{ }^{86} \mathrm{Sr}_{i}$ vs ${ }^{143} \mathrm{Nd} /{ }^{144} \mathrm{Nd}_{i}$ para as rochas de Indaiá I e II, bem como suas encaixantes. Curvas de mixing isotópico são apresentadas, tendo como polos: o fundido calculado de Indaiá I e o fundido calculado da encaixante crustal. Também representados os fundidos de Indaiá I calculados por Guarino et al. (2013), e as composições de rocha total de Indaiá I e da encaixante. As porcentagens nos gráficos referem-se ao percentual de incorporação de material crustal. As composições de Indaiá II fitam a curva de mistura. .82 Figura 44 Modelo esquemático ilustrando a contaminação pela incorporação de fundidos anatéticos ocorrida em Indaiá II. Essa contaminação provavelmente foi mais eficiente no topo da intrusão onde a perda de calor é mais eficiente. A contaminação é auxiliada através do fluxo turbulento durante a colocação do magma ( representado na figura pelas setas amarelas). Nesse modelo a contaminação se concentra na parte superior da câmara, devido a maior interação com os fundidos e menor densidade dos fundidos crustais. 84 


\section{LISTA DE TABELAS}

Tabela 1: Sumário petrográfico das rochas da intrusão Indaiá II. Valores das concentrações minerais em porcentagem em volume (\% vol.).

Apêndice A - Tabela 1 Composição em óxidos (\% massa) e fórmula estrutural das olivinas da intrusão Indaiá II (continua)

Apêndice A - Tabela 2 Composição de elementos traço (em ppm) obtidas por laser ablation-ICP-MS das olivinas da intrusão Indaia II (continua)

Apêndice A - Tabela 3 Valor preferido do padrão BHVO-2G para o controle de qualidade (continua)

Apêndice A - Tabela 4 Valor preferido do padrão NIST610 para o controle de qualidade

Apêndice A - Tabela 5 Valor preferido do padrão NIST612 para o controle de qualidade 126

Apêndice A - Tabela 6 Composições (\% em massa) e formula estrutural dos piroxênios da intrusão Indaia II (continua)

Apêndice A - Tabela 7 Composições (\% em massa) e formula estrutural das micas da intrusão Indaia II (continua)

Apêndice A - Tabela 8 Composições (\% em massa) e formula estrutural dos espinélios da intrusão Indaia II (continua)

Apêndice A - Tabela 9 Composições (\% em massa) e formula estrutural das perovskitas da intrusão Indaia II (continua)

Apêndice B - Tabela 10 Dados de análises de elementos maiores e traços em rocha total por FRX e ICP-MS (continua)

Apêndice B - Tabela 21 Dados de análises isotópicas em rocha total dos sistemas Rb-Sr e Sm-Nd. Dados obtidos $\left({ }^{87} \mathrm{Sr} /{ }^{86} \mathrm{Sr},{ }^{143} \mathrm{Nd} /{ }^{144} \mathrm{Nd}\right)$ e corrigidos para $80 \mathrm{Ma}\left({ }^{87} \mathrm{Sr} /{ }^{86} \mathrm{Sr}_{80 \mathrm{Ma}},{ }^{143} \mathrm{Nd} /{ }^{144} \mathrm{Nd} 80 \mathrm{Ma}\right)$. Também incluídos idades modelo e valores de épsilon $\mathrm{Sr}$ e Nd.

Apêndice C - Tabela 12 coeficientes de partição para magmas de composição riolítica compilados a partir da literatura (Rollinson, 1993; Nielsen, 2006)

Apêndice C - Tabela 23 Composições de elementos maiores e traços dos fundidos gerados a partir do RhyoliteMelts, e porcentagem em massa dos fundidos e resíduos sólidos.

164

Apêndice C - Tabela 34 Composições recalculadas dos fundidos e Indaiá I e II e composição média dos núcleos de olivina extraídas por balanço de massa (continua) 



\section{INTRODUÇÃO}

\subsection{Introdução e objetivos}

O comportamento magmático de sistema aberto envolve uma série de processos nos quais ocorre troca de massa e energia entre um corpo de magma e seu ambiente externo (Streck, 2008). Dentre esses processos, geralmente são considerados os principais a interação entre o magma e rochas encaixantes (digestão de xenólitos, introdução fundidos parciais ou fluidos etc.) e mistura entre magmas de composições distintas (Leeman e Hawkesworth, 1986). Tais trocas de material e energia induzem mudanças nos parâmetros físico-químicos do magma e consequente desequilíbrio entre o fundido contaminado ou hibridizado e a assembleia mineral cristalizada previamente. O registro geológico desses processos pode ser investigado através do estudo das variações químicas, isotópicas e texturais dos minerais e rochas cristalizados a partir destes magmas (Streck, 2008).

Magmas alcalinos ultrabásicos fortemente insaturados em sílica como os de afinidade kimberlítica e kamafugítica, tendem a apresentar uma forte interação com a crosta continental. Isso ocorre em função de suas temperaturas relativamente altas (Sparks et al., 2009; Fedortchouk e Canil, 2004; Stoppa e Sharygin, 2009), composição exótica contrastante com a da crosta, e de sua natureza reativa devido ao alto conteúdo de componentes voláteis, principalmente $\mathrm{CO}_{2}$ e $\mathrm{H}_{2} \mathrm{O}$ (Vuorinen e Skelton, 2004). Tais características levam esses magmas a terem como tendência principal o comportamento de sistemas abertos.

Contudo os estudos focados na interação entre esses magmas e a crosta ainda não são abundantes. Isso se deve em parte ao enfoque muitas vezes econômico dado a essas rochas, mas principalmente ao seu alto conteúdo de elementos incompatíveis, por vezes mais elevado do que na crosta. Isso implica que mesmo a incorporação de material crustal induza pequena mudança nas características de elementos-traço e isotópicas desses litotipos (Albarède, 1995; Faure, 2001).

Soma-se a isso a incerteza da composição representativa de um fundido nessas rochas (Sparks, 2013). Tal incerteza se deve a dois fatores principais: a primeira fonte de incerteza deve-se a seu caráter ultramáfico rico em voláteis, que faz com que essas rochas sejam muito susceptíveis a alteração intempérica e hidrotermal. A segunda fonte de incerteza é a abundante população de xenocristais e xenólitos do manto e da crosta, incorporados ao magma e carregados durante sua rápida ascensão através da litosfera. Dentre a carga de xenocristais do manto carregados por esses magmas o principal componente é a olivina, que em magmas 
kimberlíticos é considerada dominantemente xenocristalina. Recentemente, alguns trabalhos trouxeram contribuições na caracterização química de elementos menores e traço em olivina, visando distinguir populações de fenocristais e xenocristais, e também distinguir alguns processos petrológicos envolvidos na gênese desses magmas (p.ex., Bussweiler et al., 2015; Foley et al., 2013)

Esta dissertação de mestrado fez uso de petrografia, geoquímica de rocha-total, química mineral e análises isotópicas de rocha-total da intrusão ultrapotássica Indaiá II , Província Alcalina do Alto Paranaíba (MG), cuja classificação ambígua entre kimberlito e kamafugito dividiu alguns autores (Meyer et al., 1994; Gibson et al., 1995; Silva, 2008), com a finalidade de caracterizá-la em detalhe e melhor compreender sua geração, processos evolutivos, e a influência dos processos magmáticos de sistema aberto em sua petrogênese. Também, buscouse entender sua possível associação com a intrusão vizinha Indaiá I, de afinidade kimberlítica (Meyer et al., 1994; Gibson et al., 1995; Silva, 2008). Também foram feitas análises de elementos-traço em olivina, visando estabelecer relações genéticas dos macrocristais (fenocristais ou xenocristais) e inferências sobre fontes e processos no manto.

Essa dissertação está organizada da seguinte maneira: o capítulo 1 aborda uma síntese do contexto geológico do trabalho. O capítulo 2 descreve os métodos analíticos utilizados e o capítulo 3 apresenta a descrição dos resultados obtidos a partir desses métodos utilizados. O capítulo 4 apresenta as discussões envolvendo o teste de hipóteses petrológicas e um modelo geológico sugerido, e o capítulo 5 sumariza as conclusões do trabalho.

\subsection{Contexto geológico}

\subsubsection{Província Ígnea Alcalina Alto Paranaíba}

As ocorrências estudadas neste presente trabalho localizam-se na Província Alcalina Alto Paranaíba (APAP), oeste do estado de Minas Gerais, Brasil (Figura 1). Essa extensa província ígnea alcalina foi definida primeiramente por Almeida (1983), em seu clássico trabalho de revisão sobre as ocorrências alcalinas do Jurássico Superior ao Eoceno no Brasil, Paraguai e Uruguai.

Essa província é notável por hospedar uma das maiores ocorrências magmáticas máficas-ultramáficas de natureza potássica, com cerca de $2000 \mathrm{~km}$ de extensão e mais de 20x10 $\mathrm{Km}^{3}$ de volume (Gibson et al., 1995; Gomes e Comin-Chiaramonti, 2005; Araujo et al., 2001). A APAP compreende as rochas vulcânicas e vulcanoclásticas kamafugíticas da Formação Mata da Corda, grandes complexos alcalino-carbonatíticos e pequenas intrusões de 
rochas alcalinas fortemente insaturadas em sílica, de natureza potássica a ultrapotássica, como kimberlitos, lamprófiros ultramáficos e kamafugitos (Gibson et al., 1995; Gomes e CominChiaramonti, 2005; Guarino et al., 2013).

Algumas dessas ocorrências hospedam depósitos de interesse econômico de Elementos Terras-Raras, Fósforo, Titânio e Diamante, como por exemplo os depósitos de Nióbio dos complexos alcalino-carbonatíticos de Araxá e Tapira, e ocorrências de Diamante como no kimberlito Três Ranchos IV (Biondi, 2005; Guarino et al., 2013).

Diversos trabalhos foram realizados para constringir a idade dos eventos magmáticos da Província Alcalina Alto Paranaíba. Na década de 1960 e 1980 alguns trabalhos realizaram datações, principalmente pelo método K-Ar, em rochas alcalinas da região (p.ex.: Hasui and Cordani, 1968; Hama et al., 1979; entre outros). Sonoki e Garda (1988) compilaram essas idades e as corrigiu para as constantes de decaimento propostas por (Steiger e Jäger, 1977). Essas correções resultaram em idades de: 83,4 - 83,7Ma para Serra Negra; 82,5 - 86,3Ma para Salitre; 89,4-77,4Ma para Araxá (separados de biotita /flogopita); 85,6-71.2Ma para Tapira (separados de biotita); 85Ma para Catalão (rocha total); e 79,7 para Pântano (rocha total). Sgarbi et al. (2004) propõe 75 - 81Ma como o intervalo de idades dos kamafugitos da Província, através de datação U-Pb em perovskita. Mais recentemente Guarino et al. (2013) determinaram por meio de datações U-Pb em perovskita um intervalo de 91-78 Ma (Cretáceo Superior) para a província como um todo, sugerindo idades um pouco mais antigas para as ocorrências kimberlíticas ( 91-80 Ma), e mais jovens para kamafugitos ( 81-78 Ma) e lamprófiros ultramáficos (flogopita picritos; $\sim 90-82 \mathrm{Ma}$ ).

A alta razão entre elementos terras raras leves e pesados, e o caráter potássico exibidos pelos magmas da APAP parece indicar a presença de veios ricos em flogopita e anfibólio na fonte mantélica desses magmas, o que é corroborado pela presença de xenólitos do manto ricos em k-richterita e flogopita em algumas lavas da província (Gomes e Comin-Chiaramonti, 2005). Carlson et al., (1996) e Araujo et al., (2001) argumentam em favor de fontes litosféricas para os magmas da APAP com base em comparações entre idades modelo dos sistemas isotópicos de $\mathrm{Sm}-\mathrm{Nd}$ e Re-Os e razões de ${ }^{187} \mathrm{Os} /{ }^{188}$ Os. Esses dados apontam que o manto foi enriquecido por elementos incompatíveis litófilos a cerca de $1 \mathrm{Ga}$, durante a formação de eventos orogênicos na borda oeste do Cráton São Francisco. Esses autores também consideram que a fonte dessas rochas alcalinas consistem em um manto metassomatizado, contendo veios ricos em clinopiroxenio e anfibólio similares ao modelo de vein-plus-wallrock-melting de Foley 
(1992). Guarino et al. (op cit) também apontam que o caráter fortemente insaturado em sílica, rico em $\mathrm{CaO}$ e voláteis $\left(\mathrm{CO}_{2}\right.$ e $\left.\mathrm{H}_{2} \mathrm{O}\right)$, e não tão rico em álcalis, não poderia ser formado por um lherzolito comum de 4 fases, e tem como fonte mais provável um manto lherzolítico enriquecido em voláteis, com uma assembléia mineral metassomatizada por veios ricos em flogopita e carbonatos.

Entre os modelos geodinâmicos propostos para província inclui-se como fonte termal o impacto da pluma de Trindade no Cráton São Francisco, onde a borda menos espessa correspondente a transição do cráton com a faixa móvel adjacente (Faixa Brasília) agiu como um "thinspot", fundindo preferencialmente a litosfera metassomatizada, menos refratária (Gibson et al., 1995). Bizzi et al. (1995) baseados na anomalia Dupal nas composições isotópicas de $\mathrm{Sr}-\mathrm{Nd}-\mathrm{Pb}$, também presente na Elevação do Rio Grande e na Cadeia de Walvis, consideraram que a fonte da APAP foi modificada isotopicamente pelo hotspot de Tristan da Cunha. Baseados na ausência da assinatura isotópica tipicamente litosférica, padrão errático de distribuição de idades e forte controle tectônico ligado a descontinuidades litosféricas, trabalhos mais recentes argumentam que o magmatismo da APAP está relacionado a reativação de profundas falhas litosféricas, e variação de campos de tensão da placa permitiram a geração e colocação dessas ocorrências (Riccomini et al., 2005; Guarino et al., 2013). 


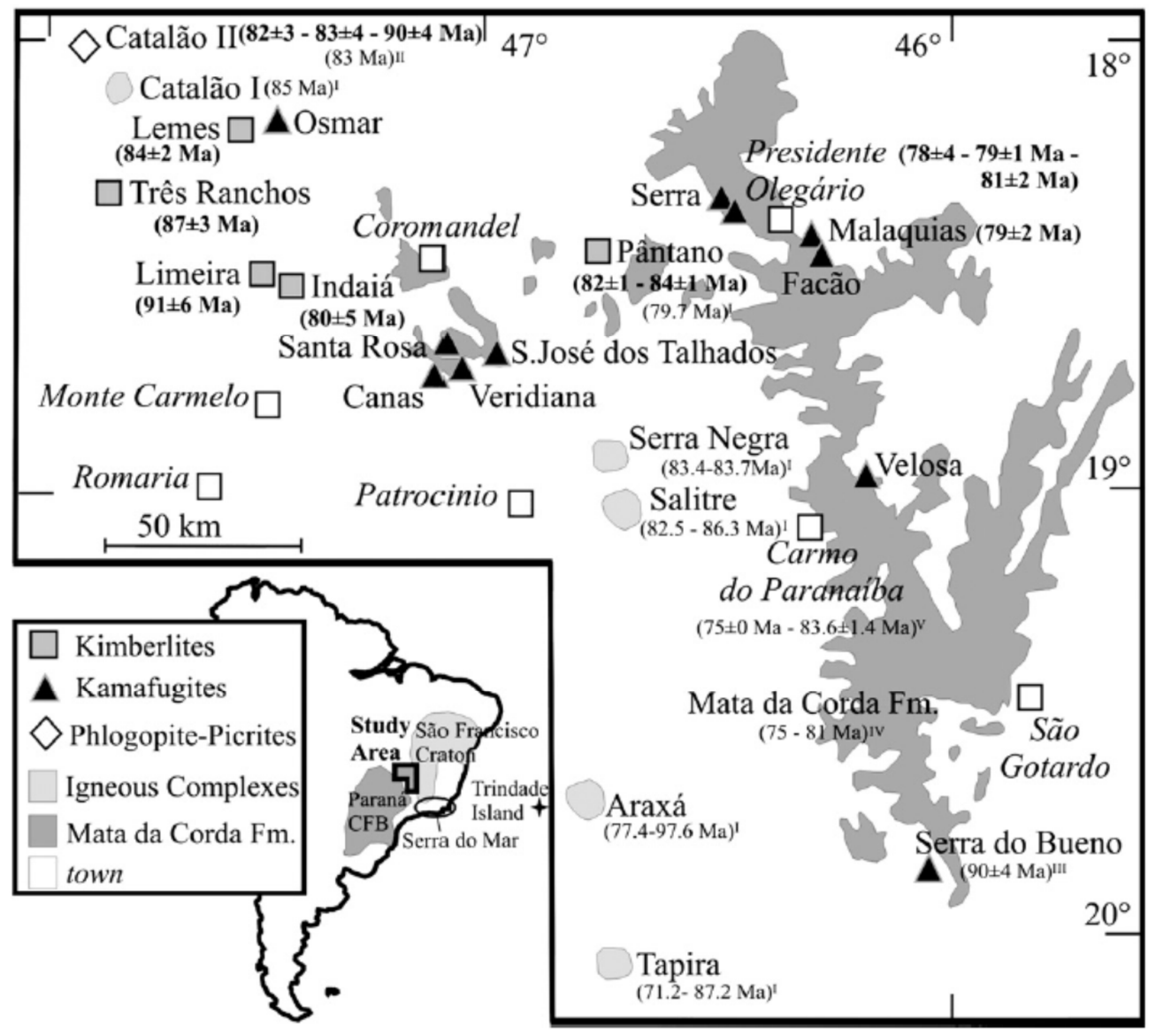

Figura 1. Localização e idades de algumas ocorrências magmáticas da Província Ígnea do Alto Paranaíba. extraído de Guarino et al. (2013) 


\subsubsection{As intrusões Indaiá I e II}

As Intrusões Indaiá I e II são corpos alcalinos ultrabásicos de tendência alcalina pertencentes a Província ígnea do Alto Paranaíba. Dentro da província localizam-se no Supercampo Kimberlítico Coromandel - Três Ranchos (Cabral Neto et al., 2017) área compreendida entre os municípios e Catalão (Go) e Patrocínio ( $\mathrm{Mg}$ ) (figura 2). Essa região estende-se por uma área de $11.600 \mathrm{~km}^{2}$, e contém uma concentração anômala de corpos kimberlíticos (lato sensu, 580 ocorrências), intrudidos em rochas da Faixa Brasília (Neoproterozóico).

A via de localização dos corpos é uma estrada vicinal que parte da rodovia MG -190, ligeo as vilas de Monte Carmelo e Abadia dos Dourados no Oeste Mineiro.

As intrusões estão encaixadas em rochas granitoides cataclasados do Complexo Monte Carmelo (Seer e Moraes, 2013), conforme pode ser observado no mapa da figura 3. As encaixantes são encontradas aflorando na forma de blocos na estrada de terra que passa entre as intrusões.

Indaiá I é a intrusão principal com cerca de 3.2 ha, já Indaiá II é a intrusão satélite, distante cerca de $100 \mathrm{~m}$ NE da intrusão principal, e de diâmetro de aproximadamente $150 \mathrm{~m}$ (figura 3b). A intrusão aflora como rocha fresca em uma drenagem, e é caracterizada por uma anomalia avermelhada no solo. Já a intrusão Indaiá II, destaca-se como um pequeno morrote, cercado por vegetação. Consiste de um afloramento de blocos de coloração cinza-esverdeada, granulação muito fina e alta densidade. Ambos os corpos tiveram seu contorno aproximado definido por métodos geofísicos (Haralyi e Svisero, 1984).

Apesar da proximidade entre os corpos, as intrusões possuem características petrográficas distintas. Indaiá I representa um kimberlito hipoabissal macrocristalino do Grupo I típico, apresentando macrocristais de olivina, diopsídio, flogopita, ilmenita magnesiana e cromita em uma matriz rica em serpentina monticellita, carbonato, perovskita, apatita e espinélio (Meyer et al., 1994; Silva, 2008). Já a Intrusão Indaiá II é textural e mineralogicamente diferenciada: mais pobre em macrocristais, tendo como olivina e flogopita como principais representantes, uma matriz composta majoritariamente por diopsídio microlítico, ausência de monticellita, e minerais acessórios similares. A rocha apresenta estrutura de fluxo, definida pela orientação dos minerais da matriz e por enclaves estirados, formados principalmente por diopsídio, kalsilita e vidro amarelado devitrificado. Esses são 
denominados por Meyer et al., (1994) de “schilieren”, em alusão à clássica estrutura observada em migmatitos.

Quimicamente, Indaiá II é diferente de qualquer kimberlito conhecido, possui caráter ultrapotássico sendo similar com os kamafugitos de Toro-Ankole, levando alguns autores a classificar a ocorrência como de afinidade kamafugítica (Meyer et al., 1994; Gomes e CominChiaramonti, 2005). Contudo Silva (2008) descarta essa classificação baseando-se na ocorrência de feldspatoides restrita ao interior de xenólitos, classificando-a como Kimberlito.

Vale ressaltar que Cabral Neto et al. (2017) no trabalho que faz parte de um conjunto de informações atualizadas sobre a geologia do diamante de Minas Gerais vinculado ao Projeto Diamante Brasil (CPRM), utiliza nomenclatura diferente para essas intrusões considerando Indaiá I como Perdizes 3-A e Indaiá II como Perdizes 3-B. Essa escolha foi feita pelo autor para evitar conflito entre a nomenclatura usada nos trabalhos acadêmicos da área, e na nomenclatura utilizada pelas empresas que realizaram trabalhos de exploração na área. Contudo nesse trabalho será mantida a nomenclatura original Indaiá I e II. 


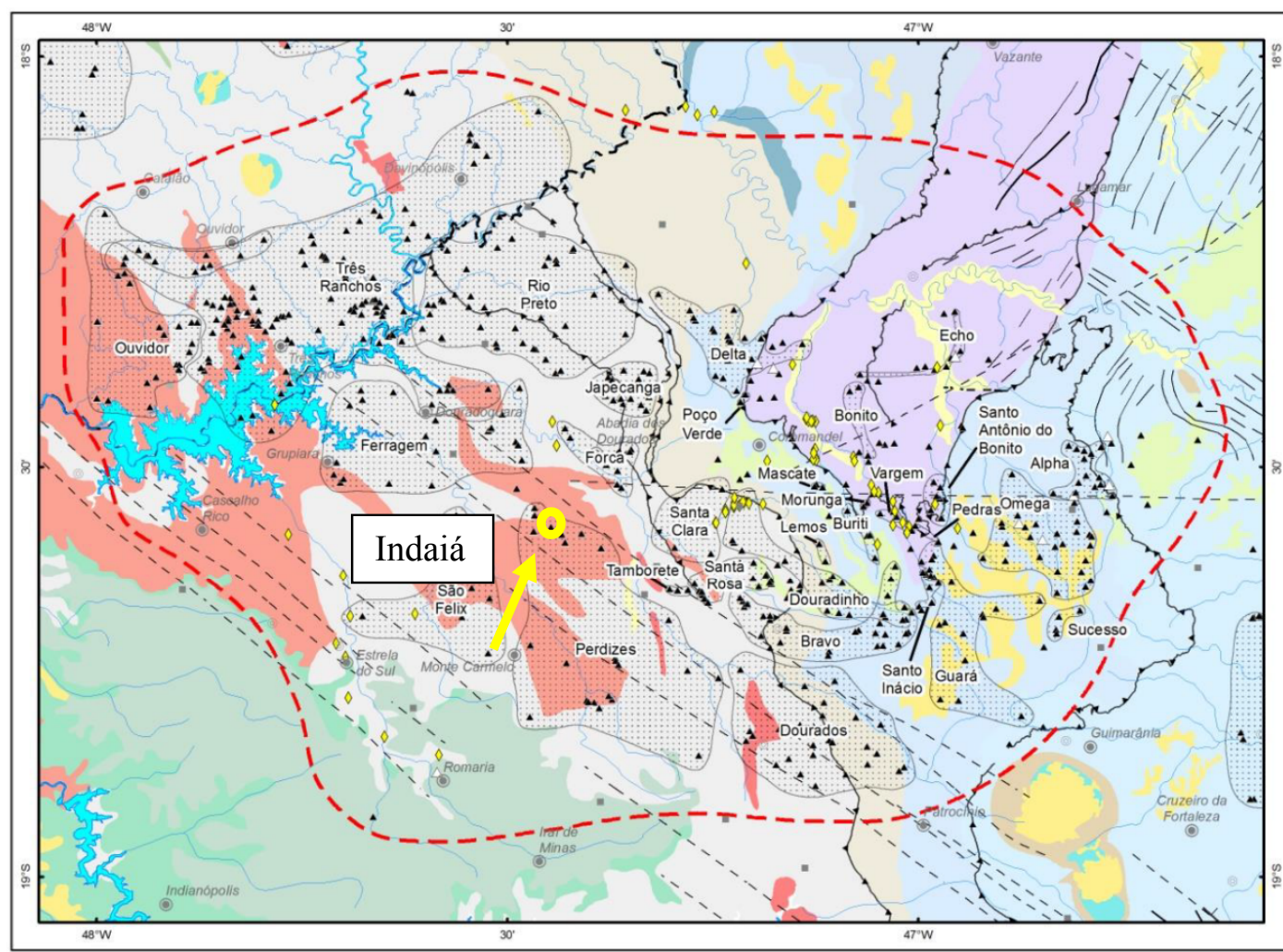

Cenozoico

Depósitos Aluvionares

Cob. Sup. Indiferenciadas

Mesozoico

Complexos Alcalinos

Fm. Mata da Corda

Fm. Marilia

Fm. Serra Geral

Gr. Areado

Neoproteozoico

Fm. Três Marias

Subgr. Paraopeba

Fm. Rio Verde

Fm. Cubatão

Gr. Araxá

Granitos Indiferenciados

Seq. M.V.S. Rio Verissimo

Mesoproteozoico

Gr. Canastra Indiviso

Fm. Paracatu

Gr. Vazante

Gr. Paranoá

Paleoproteozoico

Suite Jurubatuba

Cidade
Vila
= Povoado
Outras Localidades
Rios e Igarapés
Corpos d'Água

$\diamond$ Ocorrências de Diamantes

- Falha ou Zona de Cisalhamento Contracional

$\triangle$ Corpos Kimberliticos Mineralizados

L Falha ou Zona de Cisalhamento Extensional

- Outras Localidades

こ। $I_{\text {Coromandel }- \text { Trés Ranchos }}^{\text {Supramo Kilico }}$

- - Lineamentos Geofísicos

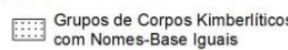
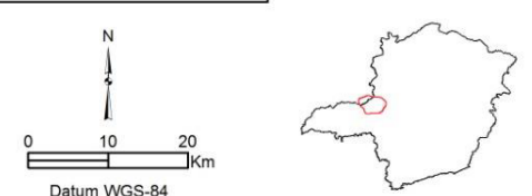

Figura 2 Mapa geológico do Supercampo kimberlítico Coromandel-Três Ranchos com intrusões de afinidade kimberlítica indicada pelos triângulos pretos. Círculo amarelo mostrando a intrusão alvo. Modificado de Cabral Neto et al. (2017). 


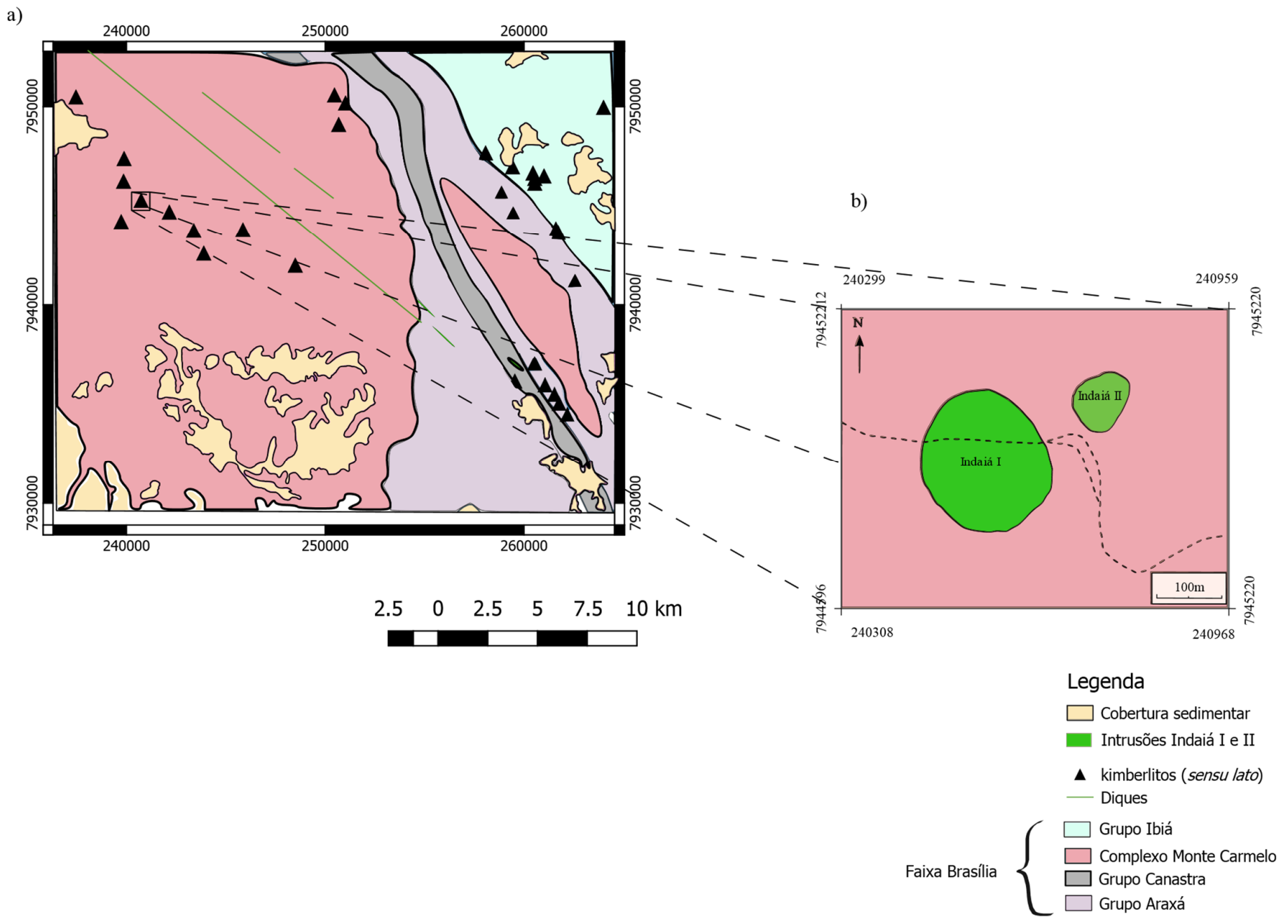

Figura 3 a) Mapa geológico esquemático modificado de Féboli e Pinheiro (2014)b) Mapa geológico esquemático das intrusões Indaiá I e II, modificado de Meyer et al. (1991). 


\section{CONCLUSÕES}

A Intrusão Indaiá II mostra uma relação genética com a Intrusão vizinha Indaiá I, de afinidade kimberlítica, onde Indaiá II apresenta clara influência de processos de contaminação crustal na sua evolução. Esse processo é demonstrado por evidências mineralógicas, texturais e geoquímicas, sejam elas:

I) A presença de diopsídio de granulação fina e flogopita desenvolvidos a partir da reação do magma e xenólitos crustais, associados a texturas de desequilíbrio e reabsorção em macrocristais e microcristais de olivina, indicando comportamento de sistema aberto.

II) Feições indicativas de fusão parcial em xenólitos graníticos parcialmente preservados e schilierens com feldspatóides, produzidos por possíveis reações de dessilicificação com o fundido.

III) Trends de química mineral associados com contaminação crustal como flogopitas ricas em Ti e Ba e espinélios com trend da titanomagnetita.

IV) Alto índice de contaminação (C.I.) na geoquímica de rocha-total.

V) Modelagem geoquímica e isotópica, que indica a incorporação incompleta de cerca de $30-40 \%$ de fundidos crustais, a partir de um magma progenitor com a composição do fundido de Indaiá I.

Conclui-se que a intrusão Indaiá II representa um processo de contaminação de fundidos derivados das rochas granitoides encaixantes a um magma progenitor similar a Indaiá I, possivelmente num mesmo conduto. A afinidade geoquímica ultrapotássica, similar à kamafugítica, é atribuída à incorporação de fundidos parciais graníticos a um magma de composição kimberlítica. 


\section{REFERÊNCIAS BIBLIOGRÁFICAS}

Albarède, F., 1995, Introduction to geochemical modeling: Cambridge University Press, 543 p.

Almeida, F.F.M. de, 1983, Relações tectônicas das rochas alcalinas mesozóicas da região meridional da Plataforma Sul-Americana: Revista Brasileira de Geociências, v. 13, p. 139158.

Andrade, S., Ulbrich, H.H., de Barros Gomes, C., and Martins, L., 2014, Methodology for the determination of trace and minor elements in minerals and fused rock glasses with laser ablation associated with quadrupole inductively coupled plasma mass spectrometry (LAQ-ICPMS): American Journal of Analytical Chemistry, v. 5, p. 701.

Araujo, A., Carlson, R.W., Gaspar, J.C., and Bizzi, L. a., 2001, Petrology of kamafugites and kimberlites from the Alto Paranaíba Alkaline Province, Minas Gerais, Brazil: Contributions to Mineralogy and Petrology, v. 142, p. 163-177, doi: $10.1007 / \mathrm{s} 004100100280$.

Azzone, R.G., Montecinos Munoz, P., Enrich, G.E.R., Alves, A., Ruberti, E., and Gomes, C.B., 2016, Petrographic, geochemical and isotopic evidence of crustal assimilation processes in the Ponte Nova alkaline mafic-ultramafic massif, SE Brazil: Lithos, v. 260, p. 58-75, doi:10.1016/J.LITHOS.2016.05.004.

Azzone, R.G., Ruberti, E., Silva, J.C.L. da, Gomes, C. de B., Rojas, G.E.E., Hollanda, M.H.B.M. de, and Tassinari, C.C.G., 2018, Upper Cretaceous weakly to strongly silicaundersaturated alkaline dike series of the Mantiqueira Range, Serra do Mar alkaline province: Crustal assimilation processes and mantle source signatures: Brazilian Journal of Geology, v. 48, p. 373-390, doi:10.1590/2317-4889201820170089.

Le Bas, M.J., Le Maitre, R.W., Streckeisen, A., and Zanettin, B., 1986, A chemical classification of volcanic rocks based on the total alkali-silica diagram: Journal of Petrology, doi:10.1093/petrology/27.3.745.

Beard, J.S., Ragland, P.C., and Crawford, M.L., 2005, Reactive bulk assimilation: A model for crust-mantle mixing in silicic magmas: Geology, v. 33, p. 681-684, doi:10.1130/G21470.1.

Bédard, J.H., 1994, A procedure for calculating the equilibrium distribution of trace elements 
among the minerals of cumulate rocks, and the concentration of trace elements in the coexisting liquids: Chemical Geology, v. 118, p. 143-153, doi:10.1016/00092541(94)90173-2.

Best, M.G., 2003, Igneous and metamorphic petrology: Blackwell Publishers, 729 p.

Biondi, J.C., 2005, Brazilian mineral deposits associated with alkaline and alkaline-carbonatite complexes, in Comin-Chiaramonti, P. and Gomes, C. de B. eds., Mesozoic to Cenozoic Alkaline Magmatism in the Brazilian Platform, São Paulo, Edusp-Fapesp, p. 707-750.

Brigatti, M.F., Medici, L., Saccani, E., and Vaccaro, C., 1996, Crystal chemistry and petrologic significance of $\mathrm{Fe} 3+$-rich phlogopite from the Tapira carbonatite complex, Brazil: American Mineralogist, v. 81, p. 913-927, doi:10.2138/am-1996-7-814.

Bussweiler, Y., Foley, S.F., Prelevic, D., and Jacob, D.E., 2015, The olivine macrocryst problem: New insights from minor and trace element compositions of olivine from Lac de Gras kimberlites, Canada: Lithos, v. 220-223, p. 238-252, doi:10.1016/j.lithos.2015.02.016.

Cabral Neto, I., Nannini, F., Valdir Silveira, F., and Matos Cunha, L., 2017, Áreas kimberlíticas e diamantíferas do estado de Minas Gerais: Programa Geologia do Brasil, Série Pedras Preciosas $n^{\circ} 10$, Projeto Diamante, Serviço Geológico do Brasil - CPRM.

Canil, D., and Bellis, A.J., 2007, Ferric Iron in CaTiO3 Perovskite as an Oxygen Barometer for Kimberlite Magmas II: Applications: Journal of Petrology, v. 48, p. 231-252, doi:10.1093/petrology/eg1067.

Carlson, R.W., Esperança, S., and Svisero, D.P., 1996, Chemical and Os isotopic study of Cretaceous potassic rocks from Southern Brazil: Contributions to Mineralogy and Petrology, v. 125, p. 393-405, doi:10.1007/s004100050230.

Caro, G., Kopylova, M.G., and Creaser, R.A., 2004, The hypabyssal 5034 kimberlite of the Gahcho Kue cluster, southeastern Slave craton, northwest territories, Canada: A granitecontaminated group-I kimberlite: Canadian Mineralogist, v. 42, p. 183-207.

Clement, C.R., 1982, A comparative geological study of some major kimberlite pipes in the Northern Cape and Orange Free State: [Phd Thesis].

DePaolo, D.J., 1981, Trace element and isotopic effects of combined wallrock assimilation and fractional crystallization: Earth and Planetary Science Letters, v. 53, p. 189-202, 
doi:10.1016/0012-821X(81)90153-9.

Droop, G.T.R., 1987, A general equation for estimating Fe3+ concentrations in ferromagnesian silicates and oxides from microprobe analyses, using stoichiometric criteria: Mineralogical magazine, v. 51, p. 431-435.

Ersoy, E.Y., 2013, PETROMODELER (Petrological Modeler): a Microsoft® Excel@ spreadsheet program for modelling melting, mixing, crystallization and assimilation processes in magmatic systems: Turkish Journal of Earth Sciences, v. 22, p. 115-125.

Faure, G., 2001, Origin of Igneous Rocks: The Isotopic Evidence: Springer Science \& Business Media, 496 p., doi:10.1007/978-3-662-04474-2.

Faure, G., and Mensing, T.M., 2005, Isotopes : principles and applications.: Wiley, 897 p.

Féboli, W.L., and Pinheiro, M.A.P., 2014, Carta Geológica Preliminar, Folha SE.23-Y-A-V MONTE CARMELO, Escala 1:100.000 - CPRM - 2014:

Fedortchouk, Y., and Canil, D., 2004, Intensive variables in kimberlite magmas, Lac de Gras, Canada and implications for diamond survival: Journal of Petrology, v. 45, p. 1725-1745.

Ferracutti, G.R., Gargiulo, M.F., Ganuza, M.L., Bjerg, E.A., and Castro, S.M., 2015, Determination of the spinel group end-members based on electron microprobe analyses: Mineralogy and Petrology, v. 109, p. 153-160.

Foley, S., 1992, Vein-plus-wall-rock melting mechanisms in the lithosphere and the origin of potassic alkaline magmas: Lithos, v. 28, p. 435-453, doi:10.1016/0024-4937(92)90018-T.

Foley, S.F., Jacob, D.E., and O’Neill, H.S.C., 2011, Trace element variations in olivine phenocrysts from Ugandan potassic rocks as clues to the chemical characteristics of parental magmas: Contributions to Mineralogy and Petrology, v. 162, p. 1-20, doi:10.1007/s00410-010-0579-y.

Foley, S.F., Prelevic, D., Rehfeldt, T., and Jacob, D.E., 2013, Minor and trace elements in olivines as probes into early igneous and mantle melting processes: Earth and Planetary Science Letters, v. 363, p. 181-191, doi:10.1016/j.eps1.2012.11.025.

Foley, S.F., Venturelli, G., Green, D.H., and Toscani, L., 1987, The ultrapotassic rocks: Characteristics, classification, and constraints for petrogenetic models: Earth Science Reviews, v. 24, p. 81-134, doi:10.1016/0012-8252(87)90001-8. 
Gibson, S.A., Thompson, R.N., Leonardos, O.H., Dickin, A.P., and Mitchell, J.G., 1995, The late cretaceous impact of the trindade mantle plume: Evidence from large-volume, mafic, potassic magmatism in SE Brazil: Journal of Petrology, v. 36, p. 189-229, doi:10.1093/petrology/36.1.189.

Gomes, C.B., and Comin-Chiaramonti, P., 2005, Some notes on the Alto Paranaíba igneous province, in Comin-Chiaramonti, P. and Gomes, C.B. eds., Mesozoic to Cenozoic alkaline magmatism in the Brazilian Platform, São Paulo, Edusp-Fapesp, p. 317-340.

Grapes, R.H., 2006, Pyrometamorphism: Berlin/Heidelberg, Springer-Verlag, 275 p., doi:10.1007/3-540-29454-6.

Griffin, W.L., 2008, GLITTER: data reduction software for laser ablation ICP-MS: Laser Ablation ICP-MS in the Earth Sciences: Current practices and outstanding issues, p. 308311.

Gualda, G.A.R., and Ghiorso, M.S., 2015, MELTS_Excel: A Microsoft Excel-based MELTS interface for research and teaching of magma properties and evolution: Geochemistry, Geophysics, Geosystems, v. 16, p. 315-324.

Guarino, V., Wu, F.Y., Lustrino, M., Melluso, L., Brotzu, P., Gomes, C. de B., Ruberti, E., Tassinari, C.C.G., and Svisero, D.P., 2013, U-Pb ages, Sr-Nd- isotope geochemistry, and petrogenesis of kimberlites, kamafugites and phlogopite-picrites of the Alto Paranaíba Igneous Province, Brazil: Chemical Geology, v. 353, p. 65-82, doi:10.1016/j.chemgeo.2012.06.016.

Gudfinnsson, G.H., and Presnall, D.C., 2005, Continuous gradations among primary carbonatitic, kimberlitic, melilititic, basaltic, picritic, and komatiitic melts in equilibrium with garnet lherzolite at 3-8 GPa: Journal of Petrology, v. 46, p. 1645-1659, doi:10.1093/petrology/egi029.

Gupta, A.K., 2015, Origin of potassium-rich silica-deficient igneous rocks: New Delhi, Springer India, 536 p., doi:10.1007/978-81-322-2083-1.

Hama, M., Algarte, J.P., Kaefer, L.O., and Artur, A.C., 1979, Idade Rb/Sr e K/Ar na região sul de Minas Gerais e leste de São Paulo: Simpósio Regional de Geologia, v. 1, p. 71-86.

Haralyi, N.L.E., and Svisero, D.P., 1984, Metodologia geofísica integrada aplicada à prospecção de kimberlitos da região oeste de Minas Gerais: Revista Brasileira de 
Geociências., v. 14, p. 12-22.

Hasui, Y., and Cordani, U.G., 1968, Idades potássio-argônio de rochas eruptivas mesozóicas do oeste mineiro e sul de Goiás, in Congresso Brasileiro de Geologia, v. 22, p. 139-143.

Hibbard, M.J., 1995, Petrography to petrogenesis: Englewood Cliffs, Prentice Hall, Inc, 587 p.

Huppert, H.E., Stephen, R., and Sparks, J., 1985, Cooling and contamination of mafic and ultramafic magmas during ascent through continental crust: Earth and Planetary Science Letters, v. 74, p. 371-386, doi:10.1016/S0012-821X(85)80009-1.

Ibhi, A., Nachit, H., and El Abia, H., 2005, Titanium and barium incorporation into the phyllosilicate phases: The example of phlogopite-kinoshitalite solid solution, in Journal de Physique IV (Proceedings), EDP sciences, v. 123, p. 331-335.

Irvine, T.N., 1965, Chromian spinel as a petrogenetic indicator: Canadian Journal of Earth Sciences, doi:10.1139/e67-004.

Kjarsgaard, B.A., Pearson, D.G., Tappe, S., Nowell, G.M., and Dowall, D.P., 2009, Geochemistry of hypabyssal kimberlites from Lac de Gras, Canada: Comparisons to a global database and applications to the parent magma problem: Lithos, v. 112, p. 236-248, doi:10.1016/j.lithos.2009.06.001.

Klein, C., and Dutrow, B., 2009, Manual de ciência dos minerais: Bookman Editora.

De la Roche, H., Leterrier, J., Grandclaude, P., and Marchal, M., 1980, A classification of volcanic and plutonic rocks using R1R2-diagram and major-element analyses - Its relationships with current nomenclature: Chemical Geology, doi:10.1016/00092541(80)90020-0.

Leeman, W.P., and Hawkesworth, C.J., 1986, Open magma systems: trace element and isotopic constraints: Journal of Geophysical Research: Solid Earth, v. 91, p. 5901-5912.

Locock, A.J., and Mitchell, R.H., 2018, Perovskite classification: An Excel spreadsheet to determine and depict end-member proportions for the perovskite- and vapnikite-subgroups of the perovskite supergroup: Computers and Geosciences, v. 113, p. 106-114, doi:10.1016/j.cageo.2018.01.012.

Malarkey, J., Pearson, D.G., Kjarsgaard, B.A., Davidson, J.P., Nowell, G.M., Ottley, C.J., and Stammer, J., 2010, From source to crust: Tracing magmatic evolution in a kimberlite and 
a melilitite using microsample geochemistry: Earth and Planetary Science Letters, v. 299, p. 80-90, doi:10.1016/j.eps1.2010.08.020.

Melluso, L., Lustrino, M., Ruberti, E., Brotzu, P., de Barros Gomes, C., Morbidelli, L., Morra, V., Svisero, D.P., and D'Amelio, F., 2008, Major- and trace-element composition of olivine, perovskite, clinopyroxene, Cr-Fe-Ti oxides, phlogopite and host kamafugites and kimberlites, Alto Paranaíba, Brazil: Canadian Mineralogist, v. 46, p. 19-40, doi:10.3749/canmin.46.1.19.

Menezes, S.G. et al., 2015, The antecryst compositional influence on Cretaceous alkaline lamprophyre dykes, SE Brazil: Brazilian Journal of Geology, v. 45, p. 79-93, doi:10.1590/23174889201500010006.

Meyer, H.O.A., Garwood, B.L., Svisero, D.P., and Smith, C.B., 1994, Alkaline intrusions in western Minas Gerais, Brazil, in Proceedings of the 5th International Kimberlite Conference, Araxá, Companhia de Pesquisa de Recursos Minerais, p. 140-155.

Mitchell, R.H., 1995a, Kimberlites, Orangeites, and Related Rocks: New York, Plenum Press, $410 \mathrm{p}$.

Mitchell, R.H., 1986, Kimberlites: Mineralogy, Geochemistry, and Petrology.: New York, Plenum Press, 442 p.

Mitchell, R.H., 1995b, Perovskites: a revised classification scheme for an important rare earth element host in alkaline rocks, in Mineralogical Society Series, Chapman \& Hall, v. 7, p. $41-76$.

Mitchell, R.H., Welch, M.D., and Chakhmouradian, A.R., 2017, Nomenclature of the perovskite supergroup : A hierarchical system of classification based on crystal structure and composition: Minerological Magazine, v. 81, p. 411-461.

Morbidelli, L., Gomes, C.B., Beccaluva, L., Brotzu, P., Conte, A.M., Ruberti, E., and Traversa, G., 1995, Mineralogical, petrological and geochemical aspects of alkaline and alkalinecarbonatite associations from Brazil: Earth-Science Reviews, v. 39, p. 135-168.

Mori, P.E., Reeves, S., Correia, C.T., and Haukka, M., 1999, Development oof a fused glass disc XRF facility and comparison with the pressed powder pellet technique at Instituto de Geociencias, Sao Paulo University: Revista Brasileira de Geociencias, v. 29, p. 441-6, doi:10.5327/rbg.v29i3.715. 
Morimoto, N., 1988, Nomenclature of Pyroxenes: Mineralogy and Petrology, v. 39, p. 55-76, doi:10.1007/BF01226262.

Nielsen, R., 2006, Geochemical earth reference model (GERM) partition coefficient (Kd) database:, https://earthref.org/KDD/ (acessado em novembro de 2017).

Patterson, M., Francis, D., and McCandless, T., 2009, Kimberlites: Magmas or mixtures? Lithos, v. 112, p. 191-200, doi:10.1016/j.lithos.2009.06.004.

Perugini, D., and Poli, G., 2012, The mixing of magmas in plutonic and volcanic environments: Analogies and differences: Lithos, v. 153, p. 261-277, doi:10.1016/j.lithos.2012.02.002.

Philpotts, A.R., Pattison, E.F., and Fox, J.S., 1967, Kalsilite, diopside and melilite in a sedimentary xenolith from Brome Mountain, Quebec: Nature, v. 214, p. 1322-1323.

Putirka, K.D., 2008, Thermometers and Barometers for Volcanic Systems: Reviews in Mineralogy and Geochemistry, v. 69, p. 61-120, doi:10.2138/rmg.2008.69.3.

Reiners, P.W., Nelson, B.K., and Ghiorso, M.S., 1995, Assimilation of felsic crust by basaltic magma: Thermal limits and extents of crustal contamination of mantle-derived magmas: Geology, v. 23, p. 563, doi:10.1130/0091-7613(1995)023<0563:AOFCBB>2.3.CO;2.

Riccomini, C., Velázquez, V.F., and Gomes, C.B., 2005, Tectonic controls of the Mesozoic and Cenozoic alkaline magmatism in central-southeastern Brazilian platform., in CominChiaramonti, P. and Gomes, C.B. eds., Mesozoic to Cenozoic Alkaline Magmatism in the Brazilian Platform, São Paulo, Edusp-Fapesp, p. 31-55.

Rieder, M. et al., 1998, Nomenclature of the micas: Canadian Mineralogist, v. 36, p. 905-912, doi:10.1346/CCMN.1998.0460513.

Le Roex, A.P., Bell, D.R., and Davis, P., 2003, Petrogenesis of Group I Kimberlites from Kimberley, South Africa: Evidence from Bulk-rock Geochemistry: Journal of Petrology, v. 44, p. 2261-2286, doi:10.1093/petrology/egg077.

Rollinson, H.R., 1993, Using Geochemical Data: Evaluation, Presentation, Interpretation: London, Longman Scientific \& Technical, 352 p.

Sahama, T.G., 1974, Potassium-rich alkaline rocks, in Sørensen, H. ed., The alkaline rocks, New York, Wiley, NY, p. 96-100.

Sato, Kei, Tassinari, C.C.G., Kawashita, K., Petronilho, L., 1995, O método geocronológico 
Sm-Nd no IG-USP e suas aplicações: An. Acad. Bras. Cienc., v. 67, p. 313-336.

Seer, H.J., and Moraes, L., 2013, Within plate, arc, and collisional Neoproterozoic granitic magmatism in the Araxá Group, Southern Brasília belt, Minas Gerais, Brazil: Brazilian Journal of Geology, v. 43, p. 333-354, doi:10.5327/Z2317-48892013000200010.

Severin, K.P., 2004, Energy Dispersive Spectrometry of Common Rock Forming Minerals: Dordrecht, Springer Netherlands, doi:10.1007/978-1-4020-2841-0.

Sgarbi, P.B.A., Gaspar, J.C., and Valen??a, J.G., 2000, Clinopyroxene from Brazilian kamafugites: Lithos, v. 53, p. 101-116, doi:10.1016/S0024-4937(00)00011-6.

Silva, S.D.A., 2008, Petrografia E Química Mineral Das Intrusões Indaiá I E Indaiá Ii , Oeste Do Estado De Minas Gerais: Universidade de São Paulo.

Skinner, E.M.W., and Marsh, J.S., 2004, Distinct kimberlite pipe classes with contrasting eruption processes: Lithos, v. 76, p. 183-200.

Sonoki, I.K., and Garda, G.M., 1988, Idades K-Ar de rochas alcalinas do Brasil Meridional e Paraguai Oriental: compilação e adaptação às novas constantes de decaimento: Boletim IG-USP. Série Científica, v. 19, p. 63-85.

Sparks, R.S.J., 2013, Kimberlite Volcanism: Annual Review of Earth and Planetary Sciences, v. 41, p. 497-528, doi:10.1146/annurev-earth-042711-105252.

Sparks, R.S.J., Brooker, R.A., Field, M., Kavanagh, J., Schumacher, J.C., Walter, M.J., and White, J., 2009, The nature of erupting kimberlite melts: Lithos, v. 112, p. 429-438, doi:10.1016/j.lithos.2009.05.032.

Spear, F.S., 1993, Spear, F. S. (1993). Metamorphic Phase Equilibria and PressureTemperature-Time Paths (Mineralogi, p. 799). Washington, D.C.: Mineralogical Society of America Washington, DC, v. 1, 799 p.

Steiger, R.H., and Jäger, E., 1977, Subcommission on geochronology: Convention on the use of decay constants in geo- and cosmochronology: Earth and Planetary Science Letters, v. 36, p. 359-362, doi:10.1016/0012-821X(77)90060-7.

Stoppa, F., and Sharygin, V. V., 2009, Melilitolite intrusion and pelite digestion by high temperature kamafugitic magma at Colle Fabbri, Spoleto, Italy: Lithos, v. 112, p. 306320, doi:10.1016/j.lithos.2009.03.001. 
Streck, M.J., 2008, Mineral textures and zoning as evidence for open system processes: Reviews in Mineralogy and Geochemistry, v. 69, p. 595-622.

Tegner, C., Wilson, J.R., and Robins, B., 2005, Crustal assimilation in basalt and jotunite: Constraints from layered intrusions: Lithos, v. 83, p. 299-316, doi:10.1016/j.lithos.2005.03.007.

Torquato, J.R., and Kawashita, K., 1994, Geocronologia nuclear - O método Rb/Sr: Revista de Geologia, v. 7, p. 91-123.

Ubide, T., Arranz, E., Lago, M., Gal??, C., and Larrea, P., 2012, The influence of crystal settling on the compositional zoning of a thin lamprophyre sill: A multi-method approach: Lithos, v. 132-133, p. 37-49, doi:10.1016/j.lithos.2011.11.012.

Vernon, R.H., 2004, A Practical Guide to Rock Microstructure:, doi:10.1017/CBO9780511807206.

Vuorinen, J.H., and Skelton, A.D.L., 2004, Origin of silicate minerals in carbonatites from Alnö Island, Sweden: Magmatic crystallization or wall rock assimilation? Terra Nova, v. 16, p. 210-215, doi:10.1111/j.1365-3121.2004.00557.x.

Yavuz, F., 2013, WinPyrox: A Windows program for pyroxene calculation classification and thermobarometry: American Mineralogist, v. 98, p. 1338-1359, doi:10.2138/am.2013.4292. 